\title{
Próba łączenia kompozytów metalowo-ceramicznych za pomocą spawania metodą TIG
}

\author{
Direct current TIG welding of metal matrix composites
}

\begin{abstract}
Streszczenie
Wprowadzanie materiałów nowej generacji o podwyższonych właściwościach mechanicznych i eksploatacyjnych zwiększa niezawodność środków transportu wodnego, a tym samym bezpieczeństwo żeglugi i obniża koszty eksploatacyjne. Do tej grupy należą odlewane metalowe materiały kompozytowe. Brak jest jednak ciągle precyzyjnego i szybkiego opisu metody łączenia tych tworzyw, co znacznie utrudnia ich wykorzystanie. Dlatego trwają pracę nad doborem dobrych jakościowo metod ich spajania. W niniejszej pracy podjęto próbę łączenia odlewanych kompozytów typu AISi/SiC przez spawanie metodą TIG prądem stałym.
\end{abstract}

Słowa kluczowe: kompozyty aluminiowe-ceramiczne; spawanie TIG

\begin{abstract}
The introduction of new generation materials with improved mechanical and operational properties increases the reliability of water transport means, thus the safety of shipping, and reduces operating costs. This group includes cast metal composite materials. However, there is still no precise and quick description of the method of combining these materials, which significantly hampers their use. Therefore, work is ongoing on the selection of good quality methods of their bonding. In this work, an attempt was made to join cast AISi/SiC composites by TIG welding using direct current.
\end{abstract}

Keywords: aluminium-ceramic composites; TIG welding

\section{Wstęp}

W ostatnich latach nastąpił znaczny postęp w udoskonaleniu metod odlewniczych oraz opracowano szczegółową kontrolę procesu odlewania, co pozwoliło na uzyskiwanie produktów o złożonych kształtach i wysokiej jakości. Właściwości mechaniczne odlewów niejednokrotnie zbliżone są do tych, jakimi charakteryzują się stopy obrabiane cieplnie. Do tej grupy należą również stopy aluminiowo-krzemowe, które z powodzeniem są stosowane jako osnowa przy wytwarzaniu odlewanych zawiesinowych materiałów kompozytowych zbrojonych węglikiem krzemu. Są to materiały, które posiadają szereg korzystnych cech takich jak: bardzo wysoka odporność na ścieranie, wysoka wytrzymałość na ściskanie, duża sztywność, duża twardość, mały współczynnik rozszerzalności cieplnej, możliwość pracy w podwyższonej temperaturze, relatywnie mały ciężar, relatywna łatwość i niski koszt wytwarzania. Pomimo wielu zalet materiały te posiadają również wady. Do nich można zaliczyć: niską plastyczność, małą odporność na kruche pękanie, naprężenia wewnętrzne powstałe $w$ procesie wytwarzania, trudność łączenia elementów konstrukcyjnych wykonanych z tego typu materiałów [1,2]. Dlatego w niniejszej pracy postanowiono wykonać próbę łączenia materiałów kompozytowych przy pomocy spawania metodą TIG prądem stałym.

\section{Spawanie metodą TIG prądem stałym kompozytów odlewanych typu AISi/SiC}

Spawanie prądem stałym metodą TIG może odbywać się prądem stałym, jak i prądem przemiennym. Przy spawaniu prądem stałym, na warunki pracy ma znaczny wpływ biegunowość przyłożonego do elektrody prądu.

Przy biegunowości dodatniej (elektroda - „biegun dodatni") strumień elektronów emitowanych z powierzchni materiału przemieszcza się w kierunku elektrody. Powoduje to niekorzystny podział ciepła (ok. 30\% na materiale), czego skutkiem jest płytkie i szerokie wtopienie oraz wytapianie elektrody.

W przypadku spawania przy biegunowości ujemnej (elektroda - „biegun ujemny”) elektrony emitowane są z elektrody

Mgr inż. Konrad Ogonowski - Laboratorium Badań Nieniszczących „AR”; dr inż. Jan Wysocki - Austen Maritime Services; dr hab. inż. Katarzyna Gawdzińska, prof. AM; prof. dr hab. inż. Wojciech Przetakiewicz - Akademia Morska w Szczecinie.

Autor korespondencyjny/Corresponding author: kogon@wp.pl 
w kierunku materiału. Uzyskuje się wtedy głębokie wtopienie, ale bez efektu usuwania warstewki tlenków z powierzchni spawanego materiału.

\section{Materiał badawczy}

Odlewy wykonano poprzez mieszanie ciekłej osnowy będącej stopem technicznym (rys. 1) ze stałym zbrojeniem (kompozyty zawiesinowe) [3,4]. Zawiesinę kompozytową uzyskano poprzez wprowadzanie cząstek ceramicznych SiC do ciekłej osnowy stopu AlSi9 w trakcie mechanicznego mieszania zachowując wszelkie parametry procesu zgodnie z [5].

\section{Wykonanie próby spawania kompozytów}

W Zakładzie Inżynierii Materiałów Okrętowej Akademii Morskiej w Szczecinie wykonano próby spawania prądem stałym przy dwóch rodzajach biegunowości:

1) elektroda nietopliwa "biegun dodatni”, materiał rodzimy "biegun ujemny";

2) elektroda nietopliwa „biegun ujemny", materiał rodzimy "biegun dodatni”.

Wstępną próbę ręcznego spawania doczołowego metodą TIG wykonano na płytkach o wymiarach 90 x 70 x 6 mm

a)
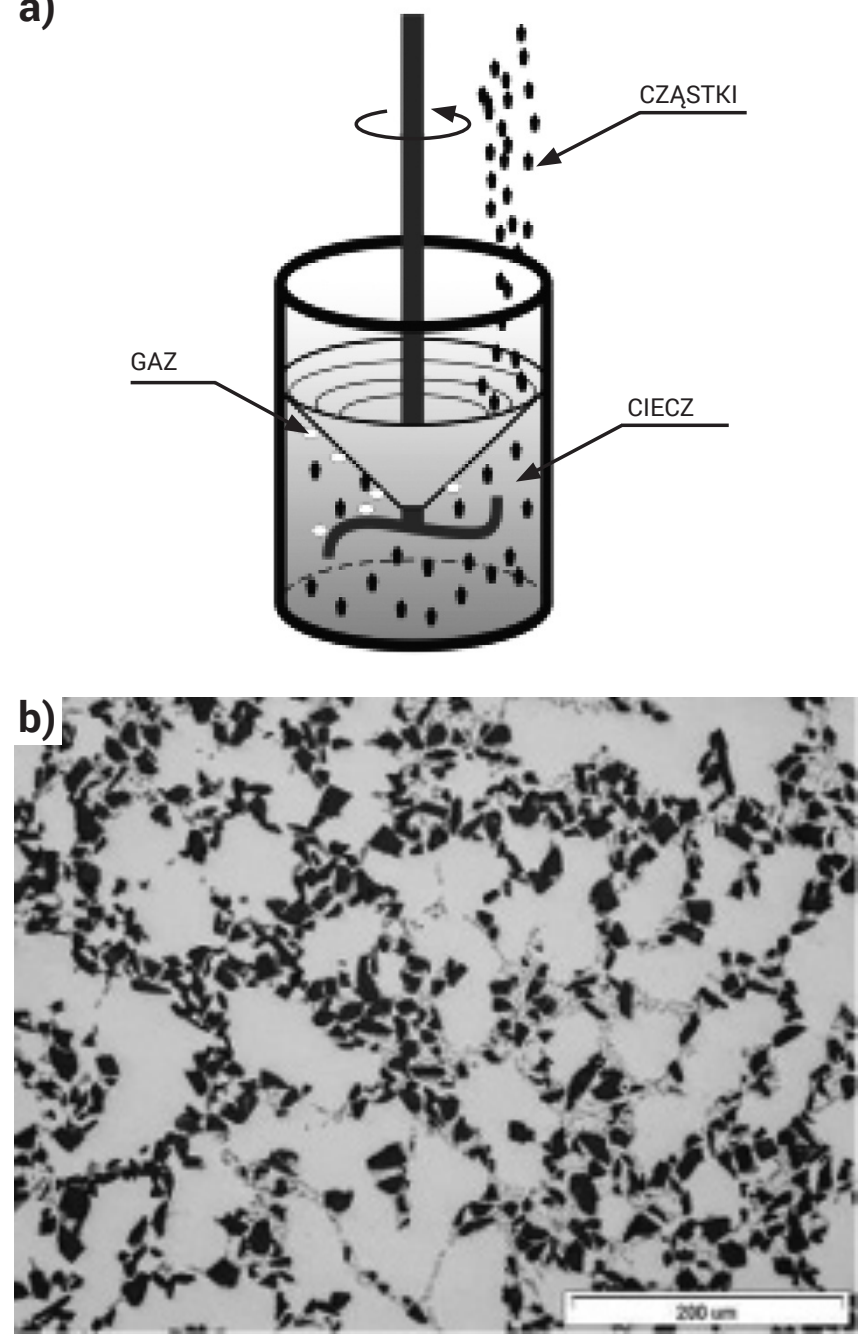

Rys. 1. Wytwarzanie kompozytów metodą mechanicznego mieszania: a) schemat, b) mikrostruktura kompozytu „ex situ” ((kompozyt zawiesinowy; mikroskopia optyczna) [3]

Fig. 1. Production of composites by mechanical mixing: a) scheme, b) microstructure of the „ex situ” composite (suspension composite; optical microscopy) [3] przy sposobie przygotowania brzegów płytek przed spawaniem na "l", spawając na podkładce miedzianej urządzeniem spawalniczym FALTIG 315 AC/DC. Wybrano elektrodę nietopliwą z wolframu o średnicy $\emptyset 2,4 \mathrm{~mm}$. Jako gazu ochronnego użyto Ar o czystości 99,996\% (numer 4,6). Natężenie przepływu gazu, dobrano doświadczalnie, wyniosło $14 \mathrm{dm}^{3} / \mathrm{min}$. Wstępna nastawa natężenia prądu wynosiła 140 A, po czym stopniowo ją obniżano do 90 A. Spawanie wykonano bez materiału dodatkowego [4].

Podczas spawania prądem stałym z biegunowością dodatnią na elektrodzie DC(+) następowało bardzo silne wytapianie elektrody wolframowej (rys. 2). Przy zmianie biegunowości „biegun ujemny na elektrodzie” następowało intensywne wytapianie metalowej osnowy, powstawanie sadzy na powierzchni krateru pochodzącej z rozpadu części cząstek SiC oraz „zbrylenia” i rozrzucania pozostałych cząstek fazy zbrojącej (rys. 3).

Niezbędne okazuje się zatem zastosowanie materiału dodatkowego. Powinien on posiadać właściwości poprawiające zwilżalność fazy zbrojącej, odznaczać się dobrą lejnością oraz spełniać rolę regulatora lepkości płynnego metalu w jeziorku spoiny [6]. Jak twierdzi Ellis [7], pozytywne rezultaty łączenia kompozytów można uzyskać stosując materiał dodatkowy 4047A o składzie bazowym Al-Si, który charakteryzuje się dobrą lejnością oraz zapobiegawczym działaniem przeciwko tworzeniu się reakcji zbrojenie/osnowa.

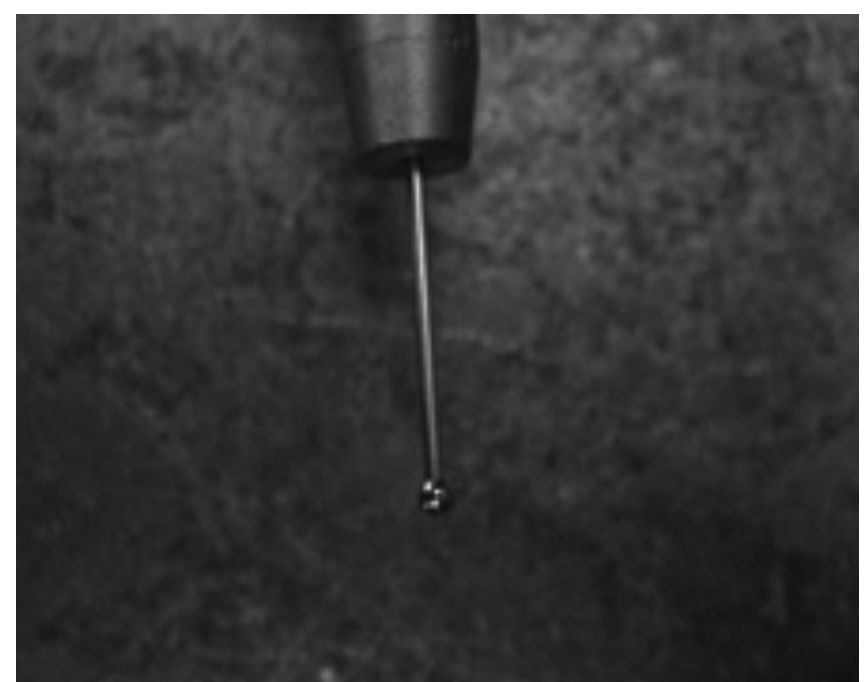

Rys. 2. Obraz makroskopowy stopionego końca elektrody wolframowej

Fig. 2. A macroscopic image of a hydrated tungsten electrode

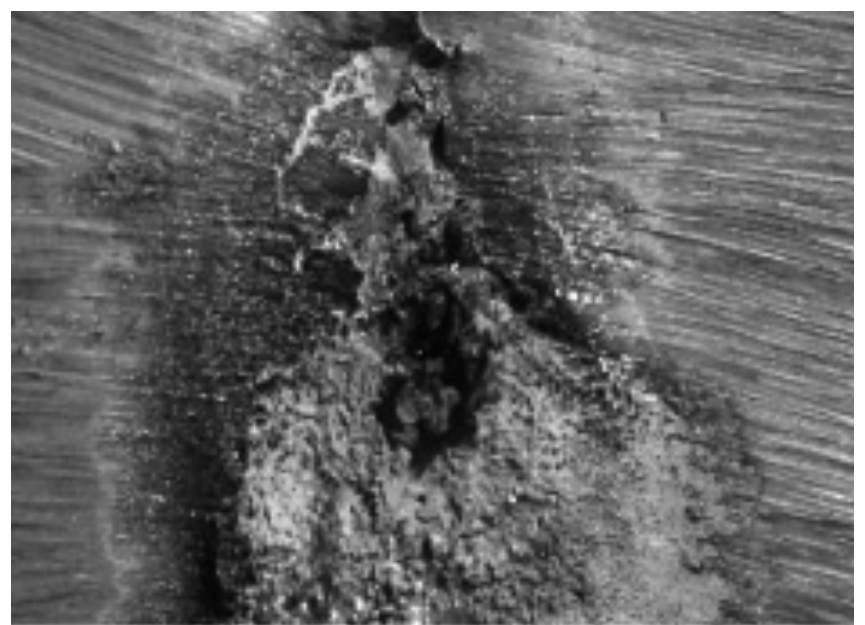

Rys. 3. Obraz makroskopowy miejsca łączenia bez materiału dodatkowego z widocznym wytopieniem metalicznej osnowy

Fig. 3. Macroscopic image of the joining site, without additional material, with visible rendering of the metallic matrix 
Ujemnymi cechami takiej kompozycji spoiwa okazało sięjego utrudnionemieszaniezroztopionymkompozytemiskłonność do tworzenia eutektyki Al-Si. Cechy te potwierdzili Lean i inni [8], używając jako materiału dodatkowego Al-Si5 (ER4043) oraz Al-Mg5 (ER5356) do próby łączenia kompozytów typu AA6082/SiC/25p oraz AA6092/SiC/25p. Stwierdzili, że mikrostruktura w strefie wpływu ciepła uwarunkowana jest wielkością energii dostarczonej podczas procesu i składu materiału dodatkowego. Przy niskiej energii łuku istnieje możliwość kontrolowania reakcji stop - zbrojenie dla obu materiałów dodatkowych. Pomimo problemów zwilżalności SiC przy materiale dodatkowym ER4043, cechą dodatnią jest zapobieganie tworzenia się Al4C3. Natomiast zastosowanie ER5356 z jednej strony powoduje lepszą zwilżalność cząstek, z drugiej jednak pozwala na zachodzenie reakcji powierzchniowych pomiędzy roztopionym stopem a cząstkami zbrojącymi. Uwzględniając wymienione spostrzeżenia, zdecydowano się zastosować drut spawalniczy ER5356 (AIMg5).

Wykonano spoiny doczołowe przy ukosowaniu krawędzi na $X$ o kącie całkowitym $60^{\circ}$, przy pojedynczym przejściu na stronę; biegunowość ujemna na elektrodzie. Pozostałe nastawy zachowano jak przy próbach bez materiału dodatkowego.
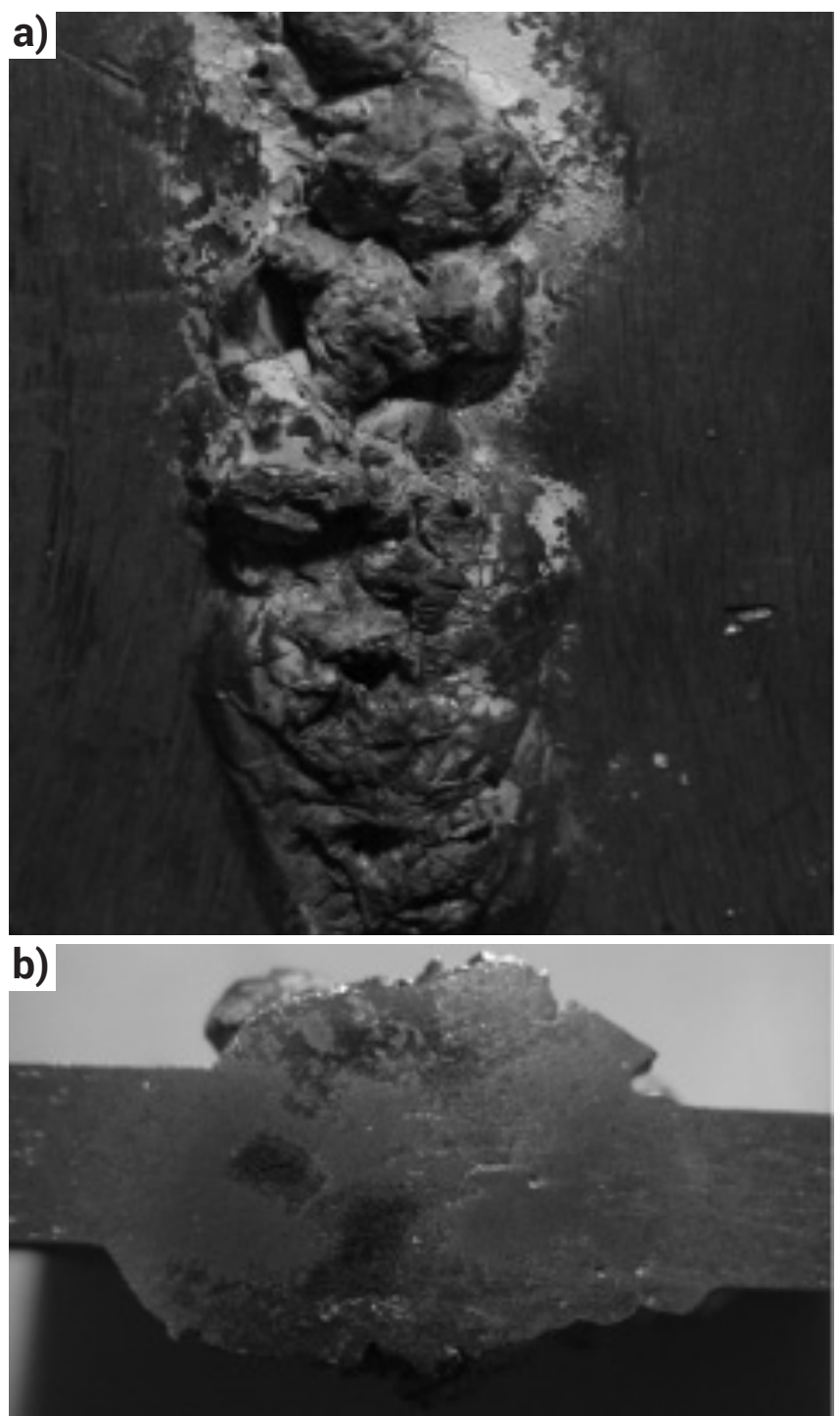

Rys. 4. Spoina wykonana metodą TIG przy prądzie stałym z biegunowością ujemną DC(-). Natężenie prądu $105 \mathrm{~A}$, ukosowanie krawędzi na X o kącie całkowitym $60^{\circ}$ : a) widok lica spoiny; b) przekrój spoiny w płaszczyźnie poprzecznej do kierunku spawania

Fig. 4. Weld produced using TIG method with constant current DC(-). Current intensity $105 \mathrm{~A}$, edge bevel to $X$ with an overall angle of $60^{\circ}$ : a) view of the weld face; b) cross-section of the weld in the plane transverse to the direction of welding
Jakość lica uzyskanego złącza spawanego budziła szereg zastrzeżeń (rys. 4a). Lico było nierównomierne z widocznymi śladami utleniania powierzchniowego, krawędzie lica nie miały charakteru ciągłości. Jednakże oględziny zgładu wykonanego w płaszczyźnie poprzecznej do kierunku spawania (rys. 4b) pozwalały stwierdzić, że przetop był pełen, lecz z oznakami porowatości.

Na rysunku 5 pokazano mikrostrukturę spoiny w obszarze linii wtopienia i bezpośrednio do niej przyległym. W obszarach, gdzie obecność cząstek SiC była bardzo mała lub nie było ich wcale (centralna część spoiny), zauważalny był rozrost dużych dendrytycznych ziaren fazy a oraz znaczna ilość eutektyk $\mathrm{a}+\mathrm{Mg}_{2} \mathrm{Si}+\mathrm{Si}$ w przestrzeniach międzydendrytycznych (rys. 5a). W obszarach eutektycznych stwierdzono wydzielenia fazy międzymetalicznej $\mathrm{Mg}_{2} \mathrm{Si}$, która widoczna była w charakterystycznej postaci "pisma chińskiego”. W strefach, gdzie nastąpiło wyraźne zagęszczenie cząstek zbrojących, zauważalne było ograniczenie rozrostu ziaren fazy a. Stwierdzono znaczną ilość drobnej eutektyki a+Si, zwłaszcza w otoczeniu cząstek SiC (rys. 5b).
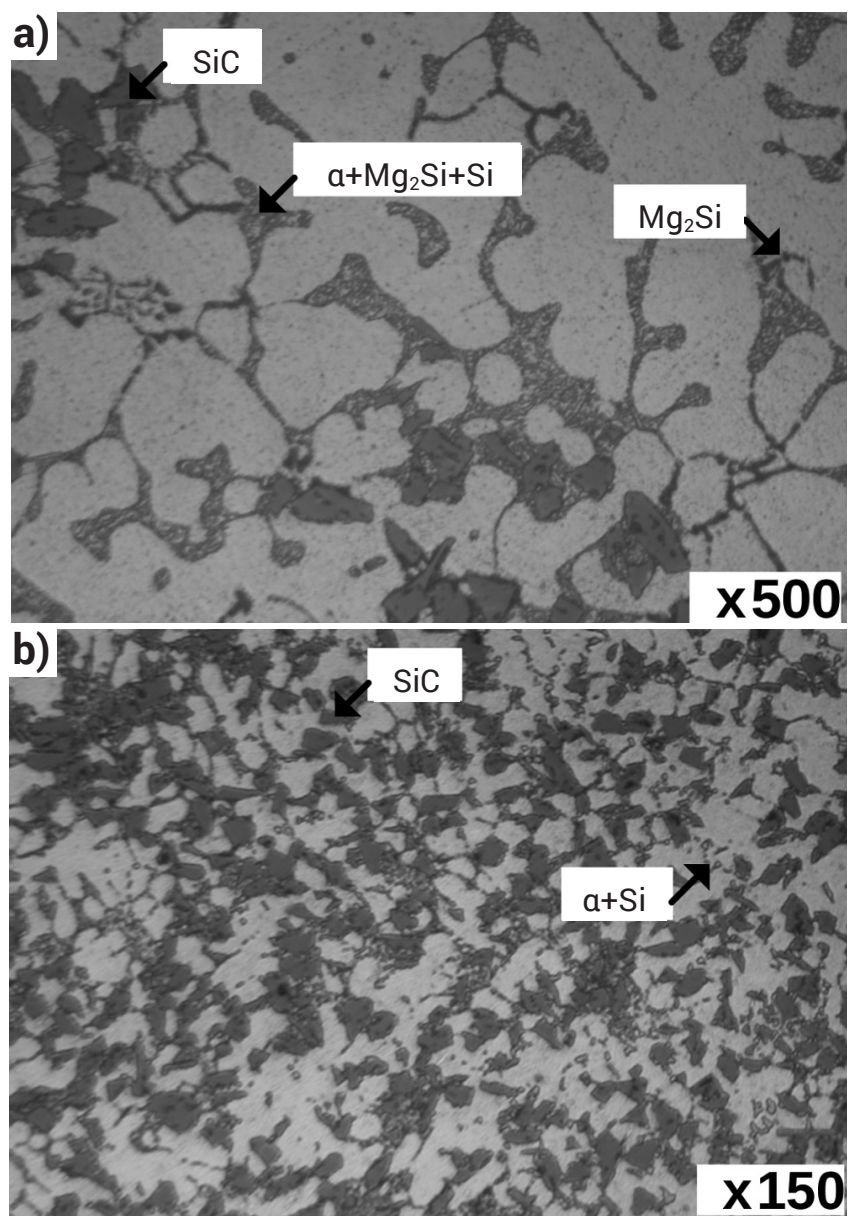

Rys. 5. Spoina wykonana metodą TIG przy prądzie stałym: a) mikrostruktura spoiny w obszarze przyległym do linii wtopienia od strony spoiny. Widoczne są niewielkie skupiska cząstek SiC, siatka eutektyki $\mathrm{a}+\mathrm{Mg}_{2} \mathrm{Si}+\mathrm{Si}$ okalającej rozrośnięte ziarna dendrytyczne fazy a oraz występujące w postaci „pisma chińskiego” wydzielenia fazy międzymetalicznej $\mathrm{Mg}_{2} \mathrm{Si}$; b) mikrostruktura spoiny w strefie zagęszczenia cząstek zbrojących. Widoczne dendrytyczne ziarna fazy a otoczone siatką eutektyki a+Si; (mikroskopia optyczna)

Fig. 5. Weld produced using TIG method with constant current: a) microstructure of the weld in the area adjacent to the fusion line from the weld side. Small clusters of $\mathrm{SiC}$ particles, $\mathrm{a}+\mathrm{Mg}_{2} \mathrm{Si}+\mathrm{Si}$ eutectic mesh, surrounding the expanded dendritic grains of the a phase and the separation of the intermetallic phase $\mathrm{Mg}_{2} \mathrm{Si}$ in the form of the "Chinese script", are visible; b) weld microstructure in the concentration zone of the reinforcing particles. Visible dendritic a phase grains surrounded by a+Si eutectic mesh; (optical microscopy) 


\section{Wnioski}

Jest możliwe połączenie kompozytów metalowo-ceramicznych przy pomocy spawania metodą TIG prądem stałym, mimo że cząstki SiC posiadają znacznie mniejszą przewodność cieplną niż metalowa osnowa [9]. Należy zatem wnioskować, że szybkość chłodzenia spoiny po skrzepnięciu ulegnie obniżeniu [10]. Takie warunki sprzyjają procesom wydzieleniowym w zakrzepłej mieszaninie nadtopionej osnowy kompozytu i materiału dodatkowego co gwarantuje ich połączenie. Zastosowanie metody TIG do spajania kompozytów odlewanych typu Al/SiC przy pomocy spawania łukowego elektrodą nietopliwą prądem stałym w osłonie gazu jest tylko fragmentem badań nad możliwościami łączenia tych tworzyw, co zostanie przedstawione w kolejnych pracach autorów.

\section{Literatura}

[1] Sobczak J.: Kompozyty metalowe, Instytut Odlewnictwa i Instytut Transportu Samochodowego, Kraków - Warszawa, 2001.

[2] Gawdzinska K., Bryll K., Nagolska D.: Influence of Heat Treatment on Abrasive Wear Resistance of Silumin Matrix Composite Castings, Arch. Metall. Mater., Vol. 61, 2016, No 1, pp. 177-182, DOI: 10.1515/amm-2016-00310.

[3] Gawdzińska K., Chybowski L., Przetakiewicz W.: Proper matrix-reinforcement bonding in cast metal matrix composites as a factor of their good quality, Archives of Civil and Mechanical Engineering, 2016, DOI: 10.1016/j.acme.2015.11.004.

[4] Wysocki J.: Spajanie kompozytów na osnowie stopów aluminiowo-krzemowych zbrojonych cząstkami węglika krzemu, Praca doktorska, Akademia Morska w Szczecinie, 2009

[5] Wojciechowski A., Sobczak J.: Kompozyty metalowe w przemyśle samochodowym, IV seminarium Kompozyty 2000, Teoria i praktyka, Częstochowa, 2000
[6] Irving B.: What's Being Done to Weld Metal-Matrix Composites, Welding Journal, pp. 65-67, June 1991.

[7] Ellis D., Gittos M.F., Threadgill P.L.: Joining Aluminium Based Metal Matrix Composites, Materials World, Vol. 2, No.8, pp. 415-417.

[8] Lean P.P., Gil L., Ureña A.: Dissimilar welds between unreinforced AA6082 and $A A 6092 / \mathrm{SiC} / 25 \mathrm{p}$ composite by pulsed-MIG arc welding using unreinforced filler alloys (Al-5Mg and $\mathrm{Al}-5 \mathrm{Si}$ ), Journal of Materials Processing Technology 143-144, 2003, pp. 846-850.

[9] Gawdzińska, K.: Quality features of metal matrix composite castings, Archives of metallurgy and materials, Vol. 58 , issue 3, 2013, pp. 659-662, DOI: 10.2478/amm-2013-005.

[10] Midling 0.T., Grong 0.: A Process Model For Friction welding Of AlMg-Si And Al-SiC Metal Matrix Composites - II. HAZ Microstructure and Strength Evolution, Acta Metallurgica Materiala, Vol. 42, No. 5, pp. 1611-1622, 1994. 